\title{
Happy People Does Not Compare : Difference in Social Comparison between Happy and Unhappy People
}

\author{
Kyoungmi Kim1)
}

\begin{abstract}
The study wanted to find out the difference between happy and unhappy groups. To this end, 451 university students were asked about subjective well-being, comparison by area, and demographic variables. And we divided the top 30 percent of the happiness level and the bottom 30 percent of the happiness level into t-test and Pearson correlations to see if there was any difference between the levels of happiness in the areas of each comparison. The results showed, first, significant differences in appearance, confidence, family background, family flower, money, ambient harmony, acceptance of others and money between happy and unhappy groups. Second, differences in appearance and money have appeared depending on gender. Third, differences in comparison appeared in other people's recognition and happiness, depending on the existence of religion. Fourth, the higher the level of happiness, the lower the degree of comparison in eight areas. These results suggest that happy people do not compare themselves with others, and that comparisons undermine happiness. Finally, the significance of this study and its suggestions for further study were discussed.
\end{abstract}

Keywords : Comparison, Subjective Well-being, Happy Group, Unhappy Group, Social, Characteristics

\section{Introduction}

One of the main social characteristics of human life is social comparison[1]. Social comparison refers to comparing one's characteristics and performance to another, and Festinger says that when one's position is uncertain, or when there is no objective standard to evaluate one's position, comparison is carried out with another person to obtain information[2]. In other words, when people are faced with uncertainty and threats, people can overcome them by comparing them with others and experience relief[3]. However, recent studies report that people who make social comparison often have low self-esteem[4], less depressed, and less happy[5].

Especially social comparison is reported as a characteristic related to happiness. Lyubomirsky

Received(April 18, 2019), Review Result(1st: May 8, 2019, 2nd: June 29, 2019), Accepted(September 10, 2019)

1) (Professor) 48520 Dept, Counseling Psychology, Tongmyong Univ., 428 Sinseon-ro, Nam-gu, Busn, Republic of Korea

email: kmkim@tu.ac.kr 
and Ross[6], for example, conducted an experiment on two groups of college students using a cross-word puzzle with one group of college students solving problems at a much faster rate than themselves, and the other group solving problems at a slower rate than themselves. After all of the cross-word puzzle, college students were instructed to evaluate their ability to correct words. As a result, happy students evaluated their abilities regardless of whether the person who solved the problem together solved it faster or slower than them, while unhappy students assessed that they lacked the abilities to correct their own words when the person who solved the puzzle submitted the card earlier than they did. In other words, it has been confirmed that unhappy people are more prone to comparison with others, which has a negative effect on mental health. These results have been proven repeatedly through experimental studies and are supported by many other studies[7][8]. Also, people who have a lot of social comparisons experience more negative emotions such as shame[9], and it appears to restore self-esteem in a temporary way, but in the long run it undermines happiness[10]. As for these reasons, those who are highly socio-comparative tend to pay attention to other people's negative assessments because of their focus on others[11]. In the end, it is easy to experience emotional instability due to maladjustment perfectionism[12]. Gibbons and Bunk also said that the more people are looking for social comparison information, the less self-esteem, the more depression and the more nervous they are[1]. This study tries to identify the characteristics of happy people by looking at whether the level of comparison between happy and unhappy people actually differs.

The preceding study argues that people who pursue external values are less happy than their intrinsic values[5][13]. For example, couples who value their relationships externally over their internal values have high love satisfaction and high level of individual happiness[14]. People with external values, such as money and fame, had less time with intimate objects such as family, friends, and lovers, and the quality of the relationship was negative[15]. In addition, studies have shown that people who pursue external values are prone to high social comparisons, thus hindering happiness[13]. For these reasons, they argue that internal values such as self-acceptance, interpersonal relationships and health are based on subjective experience, but external values such as money and appearance are easy to evaluate because they depend on social comparison information. Kim also argued for college students that materialism, which is an external value, would reduce their satisfaction with college life and happiness[5]. However, studies have recently shown that the more social pressure to be happy, the more likely it is to experience negative emotions[16], Implying the need to pay attention to other people's expectations or pressures for happiness. This suggests that even if it is an 
internal value, comparing it with others is not helpful in happiness either.

Therefore, this study seeks to find out whether happy people compare less with the inner values of happiness, relationships, etc. than with unhappy people, but also with external areas such as money, appearance, and family background. To do this, we want to find out the degree of comparison between appearance, confidence, family background, family harmony, money, harmony, recognition of others, and happiness, and see if there are any differences between happy and unhappy people in comparison to each area.

The purpose of this study is:

1) Is there any difference in comparison in each area according to demographic characteristics (sex, religion, economic level)?

2) Are there any differences in the level of comparison between happy and unhappy people in each area?

\section{Study Method}

\subsection{Participants}

A researcher conducted a survey among 451 college students in Seoul, Chungcheongnam-do, Jeollabuk-do and Gyeongsangnam-do. The average age was 22.09 (SD=1.95). A total of 204 $(45.2 \%)$ male students were surveyed and a total of $244(54.1 \%)$ female students were surveyed.

\subsection{Instruments}

1) subjective well-being : The Satisfaction With Life Scale (SWLS) and Positive and Negative Affect Scale (PANAS) are adopted to measure happiness. The SWLS is developed by Diener et al[17] and SWB uses the Positive and Negative Affect Scale (PANAS) which is developed by Watson, Clark and Tellegen[18].

The SWLS consists of five statements with $1-7$ scale in order to check overall life satisfaction. The PANAS consists of two 10-item scales to measure both positive and negative affect. Each item is rated on a 5-point scale. In this study, the Cronbach's a of the SWLS, the positive sentiment and the negative sentiment represents $.86, .85, .89$ respectively. As the index of SWLS is combined with different scales, "SWLS+ positive sentiment-negative sentiment" is calculated and analyzed with the use of $\mathrm{Z}$ score of each scale. 
2) comparison: In order to determine the degree of comparison, I asked how they compare with others in appearance, confidence, family background, family harmony, money, relation harmony, recognition of others, and happiness. Each item is rated on a 5-point scale(1=never compare. $5=$ Compare very much)

3) control variable: Age, service period, academic background (1=high school graduate or less, $2=$ college student, $3=$ college graduate, $4=$ graduate school or more) and family circumstances (1=very affluent, $6=$ very difficult) were asked.

\subsection{Data Analysis}

The collected data in this study were analyzed with SPSS 20.0. Descriptive statistics analysis was conducted to find out demographic descriptors. The difference in the degree of comparison between high happy group and low happy group was analyzed by $\mathrm{t}$-test and the relationship between variables was analyzed by Pearson's correlation coefficient. And the degree of comparison according to general characteristics was analyzed by t-test and ANOVA.

\section{Result}

\subsection{The General Characteristics of the Subjects}

The general characteristics of the subjects in this study(table 1) were 207 men $(45.9 \%)$ and 244 women $(54.1 \%)$, with an average age of 22.09 years $(\mathrm{SD}=4.25)$. There were 213 students with religion (47.2\%) and 238 students without religion (52.8\%). The economic level was high (42 persons, 9.8\%), middle (359 persons, 79.6\%), low (50 persons, 11.1\%).

[Table 1] General Characteristics of Subjects $(\mathrm{N}=451)$

\begin{tabular}{|ccc|}
\hline Characteristics & Categories & $\mathrm{n}(\%)$ or $\mathrm{M} \pm \mathrm{SD}$ \\
\hline \multirow{2}{*}{ Gender } & Male & $207(45.9)$ \\
& Female & $244(54.1)$ \\
Age & & $22.09(4.25)$ \\
Religion & Others & $213(47.2)$ \\
& None & $238(52.8)$
\end{tabular}




\subsection{Comparison according to the General Characteristics of the Subject}

If you look at how much comparisons are made by gender (Table 2), There was a significant difference with appearance $(t=5.12, p<.001)$ and money $(t=2.03$ and $p<.05)$. That is, women compared more to others about appearance and money than men.

[Table 2] Differences of Comparison by Gender

\begin{tabular}{|lccc|}
\hline comparison & Male $(\mathrm{n}=207)$ & Female $(\mathrm{n}=244)$ & \\
\cline { 2 - 4 } & Mean \pm SD & Mean \pm SD & $\mathrm{p}<.001$ \\
\hline appearance & $3.03 \pm 1.03$ & $3.54 \pm 1.04$ & $\mathrm{~ns}$ \\
confidence & $3.13 \pm 1.17$ & $3.34 \pm 1.14$ & $\mathrm{~ns}$ \\
family background & $2.42 \pm 1.17$ & $2.51 \pm 1.15$ & $\mathrm{~ns}$ \\
family harmony & $2.55 \pm 1.27$ & $2.75 \pm 1.34$ & $\mathrm{p}<.05$ \\
money & $2.82 \pm 1.11$ & $3.03 \pm 1.07$ & $\mathrm{~ns}$ \\
relation harmony & $3.29 \pm 1.15$ & $3.40 \pm 1.06$ & $\mathrm{~ns}$ \\
recognition of others & $3.35 \pm 1.20$ & $3.48 \pm 1.10$ & $\mathrm{~ns}$ \\
happiness & $3.23 \pm 1.13$ & $3.25 \pm 1.29$ & \\
\hline
\end{tabular}

When looking at how much comparisons are made according to religious presence, there was a tendency of difference in other people's recognition and happiness. In other words, people with religion compared the feelings of others more often than people without religion, and tended to make less comparisons of happiness.

The ANOVA validation of how much comparison is made according to the economic level showed no statistically significant differences in the eight comparison areas.

[Table 3] Differences of Comparison by Religion

\begin{tabular}{|lccc|}
\hline comparison & Others $(\mathrm{n}=213)$ & None $(\mathrm{n}=238)$ & \\
\cline { 2 - 4 } & Mean \pm SD & Mean \pm SD & -value \\
\hline appearance & $3.31 \pm 1.11$ & $3.32 \pm 1.03$ & $\mathrm{~ns}$ \\
confidence & $3.29 \pm 1.16$ & $3.26 \pm 1.15$ & $\mathrm{~ns}$ \\
family background & $2.55 \pm 1.14$ & $2.41 \pm 1.16$ & $\mathrm{~ns}$ \\
family harmony & $2.60 \pm 1.32$ & $2.70 \pm 1.31$ & $\mathrm{~ns}$ \\
money & $2.94 \pm 1.12$ & $2.95 \pm 1.08$ & \\
& & & \\
& & & \\
\hline
\end{tabular}


Happy People Does Not Compare : Difference in social comparison between happy and unhappy people

\subsection{Comparison between Happy and Unhappy Groups}

T-test was performed on the comparison level of eight areas by dividing the top $30 \%$ and the bottom $30 \%$ of subjective well-being. The result showed significant differences in appearance, confidence, family background, family harmony, money, harmony, recognition of others, and happiness between happy and unhappy groups. In other words, happy people made less comparisons in all areas of appearance, confidence, family background, family harmony, money, harmony, recognition of others, and happiness than unhappy people.

[Table 4] Differences of Comparison by Happiness

\begin{tabular}{|lccc|}
\hline comparison & Unhappy $(\mathrm{n}=134)$ & happy(n=135) & \\
\cline { 2 - 3 } & Mean \pm SD & Mean \pm SD & $\mathrm{p}$-value \\
\hline appearance & $3.69 \pm 1.06$ & $2.94 \pm 1.05$ & $\mathrm{p}<.001$ \\
confidence & $3.61 \pm 1.11$ & $2.85 \pm 1.26$ & $\mathrm{p}<.001$ \\
family background & $2.87 \pm 1.28$ & $2.13 \pm 1.06$ & $\mathrm{p}<.001$ \\
family harmony & $2.96 \pm 1.33$ & $2.41 \pm 1.27$ & $\mathrm{p}<.01$ \\
money & $3.39 \pm 1.10$ & $2.56 \pm 1.09$ & $\mathrm{p}<.001$ \\
relation harmony & $3.54 \pm 1.06$ & $3.18 \pm 1.24$ & $\mathrm{p}<.05$ \\
approval of others & $3.65 \pm 1.05$ & $3.11 \pm 1.29$ & $\mathrm{p}<.001$ \\
happiness & $3.71 \pm 1.08$ & $2.86 \pm 1.49$ & $\mathrm{p}<.001$ \\
\hline
\end{tabular}

\subsection{Subjective Sense of Well-being and the Relationship between Each Comparative Area}

The results of subjective well-being and comparison in each area are shown in [Table 5]. Subjective well-being showed a negative correlation in the area of each comparison. In other words, the happier a person is, the less they compare appearance, confidence, family background, family harmony, money, harmony, recognition and happiness of others.

[Table 5] Correlation among Variables

\begin{tabular}{|lllllllll|}
\hline Variables & 1 & 2 & 3 & 4 & 5 & 6 & 7 & 8 \\
\hline 1.subjective wellbeing & 1 & 00 & & & & & & \\
\hline
\end{tabular}




$\begin{array}{|lccccccccccc|}\text { 4.family background } & -27^{* * *} & .29^{* * *} & .21^{* * *} & 1.00 & & & & & & & \\ \text { 5.family harmony } & -17^{* * *} & .23^{* * *} & .26^{* * *} & .45^{* * *} & 1.00 & & & & & \\ \text { 6.money } & -32^{* * *} & .43^{* * *} & .26^{* * *} & .59^{* * *} & .42^{* * *} & 1.00 & & & & \\ \text { 7.relation harmony } & -15^{* *} & .22^{* * *} & .44^{* * *} & .18^{* * *} & .36^{* * *} & .24^{* * *} & 1.00 & & \\ \text { 8.recognition of others } & -21^{* * *} & .31^{* * *} & .43^{* * *} & .21^{* * *} & 30^{* * *} & 29^{* * *} & .64^{* * *} & 1.00 & \\ \text { 9.happiness } & -29^{* * *} & .24^{* * *} & .43^{* * *} & .28^{* *} & .47^{* * *} & .35^{* * *} & .55^{* * *} & 56^{* * *} & 1.00\end{array}$

${ }^{*} \mathrm{p}<.05,{ }^{* *} \mathrm{p}<.01,{ }^{* * *} \mathrm{p}<.001$.

\section{Conclusion}

The purpose of this study is to ensure whether happy people have less social comparison than unhappy people. The results and discussions of the analysis are as follows:

First, we looked at whether there were any differences in comparability in eight areas, depending on gender, religion, and economic level, which are the demographic characteristics. As a result, women compared their appearance and money more with others than men. People with religion were more inclined to compare other people's recognition and happiness with others than people without religion, and there was no difference in comparison according to economic. This is consistent with a previous study, which found that women are more prone to social comparisons than men[5] and that women regard appearance as a means to enhance their values[19]. Also, a group of female college students think external job values are more important than male students, and this is in line with the research result that female college students with external job values are less career-oriented[20]. This is also thought to be the result of appearanceism through mass media, and the influence of social trends that regard appearance and finances as a competitive advantage. Therefore, it is believed that education or counseling approaches will be necessary, considering the level of internal and external values, depending on gender.

People with religion could see that they wanted to be recognized by others, and that they tended to be happier than others. It is believed that people with religion tend to compare other people's recognition with happiness because they have a lot of experience emphasizing the value of good behavior and happiness within their religious experience.

Second, happy people were all higher in comparison in eight areas than unhappy people. This is consistent with the results of various prior studies on the negative relationship between happiness and social comparison. This is consistent with the findings of previous research that 
Happy People Does Not Compare : Difference in social comparison between happy and unhappy people

happy people experience less social comparison than unhappy people and experience less negative emotions due to social comparison information. This suggests that happy people do not judge themselves compared to others. Especially, happy people have high self-esteem. Therefore, it can be guessed that there is a characteristic of evaluating oneself rather than evaluating oneself by comparing with others. Since the present study did not identify the psychological mechanism, it is a careful guess, so an extended study will be required in the subsequent study.

In addition, happy people have made less comparisons not only in external areas such as money, appearance, and recognition of others, but also in internal areas such as happiness and ambient harmony. In other words, happy people do not often compare, even with their internal values, and are considered to be less conscious of social pressure on their inner values, such as happiness and relationships. Also, considering the negative relationship between level of happiness and level of comparison in all domains, it is suggested that social comparison with others is a major factor impeding happiness. Therefore, it is necessary to have education and social culture that help people to have a healthy self-image that does not compare with others and can see themselves as they are.

The limitations of this study were that the cause of the relationship between happiness and social comparison levels could not be identified. It is considered necessary to identify causative relationships through experimental or end-to-end research to identify them. It is also necessary to examine the effects of other psychological variables on the relationship between happiness and social comparison. An integrated model study is necessary considering variables such as cultural factors and personalities.

\section{Reference}

[1] B. P. Buunk, F. X. Gibbons, Social Comparison: The End of a Theory and the Emergence of a Field, Organizational Behavior and Human Decision Processes, (2007), Vol.102, No.1, pp.3-21, DOI: 10.1016/j.obhdp.2006.09.007

[2] L. Festinger, A theory of social comparison process, Human Relations, (1954), Vol.7, No.2, pp.117-140, DOI: https://doi.org/10.1177/001872675400700202

[3] L. Bogart, V. S. Helgeson, Social comparisons among women with breast cancer: A longitudinal investigation, Journal of Applied Social Psychology, (2000), Vol.30, No.3, pp.547-575, DOI: 10.1111/j.1559-1816.2000.tb02496.x

[4] J. A. Cattarin, J. K. Thompson, C. Thomas, R. Williams, Body image, mood, and televised images of 
Asia-pacific Journal of Convergent Research Interchange

Vol.5, No.3, September 30 (2019), pp. 21-30

http://dx.doi.org/10.21742/apjcri.2019.09.03

attractiveness: The role of social comparison, Journal of Social and Clinical Psychology, (2000), Vol.19, No.2, pp.220-239, DOI: $10.1521 /$ jscp.2000.19.2.220

[5] K. M. Kim, The relationship among social comparison orientation, subjective wellbeing and depression: Moderating effects of self control, Korean Journal of Youth Studies, (2016), Vol.23, No.10, pp.235-257, DOI: http://dx.doi.org/10.21509/KJYS.2016.10.23.10.235

[6] S. Lyubomirsky, L. Ross, Hedonic consequences of social comparison: A contrast of happy and unhappy people, Journal of Personality and Social Psychology, (1997), Vol.73, No.6, pp.1141-1157, DOI: 10.1037//0022-3514.73.6.1141

[7] S. Lyubomirsky, Why are some people happier than others? The role of cognitive and motivational processes in well-being, American Psychologist, (2001), Vol.56, pp.239-249.

[8] S. Lyubomirsky, K. L. Tucker, F. Kasri, Responses to hedonically conflicting social comparisons: Comparing happy and unhappy people, European Journal of Social Psychology, (2001), Vol.31, No.5, pp.511-535, DOI: 10.1002/ejsp. 82

[9] F. Fujita, The frequency of social comparison and its relation to subjective well-being, The science of subjective well-being, Guilford Press, (2008)

[10] J. B. White, E. J. Janger, L. Yariv, J. C. Welch IV, Frequent social comparisons and destructive emotions and behavior: The dark side of social comparisons, Journal of Adult Development, (2006), Vol.13, pp.36-44, DOI: https://doi.org/10.1007/s10804-006-9005-0

[11] K. H. Lee, N. R. Kim, The relationship between intolerance of uncertainty and perceived career barriers: Testing the mediating effects of social comparison orientation and fear of negative evaluation, The Journal of Vocational Education Research, (2012), Vol.31, No.4, pp.111-134, UCI: G704-000975.2012.31.4.002

[12] S. K. Son, Parent's forced sibling social comparison and emotional stability in adolescence: Mediating role of maladaptive perfectionism and social comparison orientation, The Korean Journal of Counseling and Psychotherapy, (2015), Vol.27, No.3, pp.665-683, UCI: G704-000523.2015.27.3.001

[13] J. S. Koo, E. M. Suh, Why Korean university students are less happy than U.S. counterparts? The role of relative extrinsic value orientation, social support and social comparison, Korean Journal of Counseling And Psychotherapy, (2015), Vol.29, No.4, pp.63-83, DOI: 10.21193/kjspp.2015.29.4.004

[14] K. M. Kim, S. A. Ryu, I. C. Choi, The Influence of perceived internal and external value on happiness and romantic relationship satisfaction: The mediational role of gratitude, Korean Journal Of Counseling and Psychotherapy, (2014), Vol.26, No.3, pp.637-655, UCI: G704-000523.2014.26.3.009

[15] T. Kasser, R. M. Ryan, Be careful what you wish for: Optimal functioning and the relative attainment of intrinsic and extrinsic goals, Life goals and well-being: Towards a positive psychology of human striving, Seattle, Hogrefe \& Huber Publishers, (2001)

[16] B. Bastian, M. L. Pe, P. Kuppens, Perceived social pressure not to experience negative emotion is linked to selective attention for negative information, Cognition and Emotion, (2017), Vol.31, No.2, pp.261-268, DOI: $10.1080 / 02699931.2015 .1103702$

[17] E. Diener, R. A. Emmons, R. J. Larsen, S. Griffin, The Satisfaction With Life Scale, Journal of Personality Assessment, (1985), Vol.49, No.1, pp.71-75, DOI: 10.1207/s15327752jpa4901_13

[18] D. Watson, L. A. Clark, A. Tellegen, Development and validation of brief measures of positive and 
Happy People Does Not Compare : Difference in social comparison between happy and unhappy people

negative affect: The PANAS Scales, Journal of Personality and Social Psychology, (1988), Vol.54, No.6, pp.1063-1070, DOI: 10.1037//0022-3514.54.6.1063

[19] M. K. Cho, E. J. Choi, J. W. Lee, Y. N. Lee, J. Y. Chae, Correlations in appearance, job-seeking stress and job-seeking anxiety in undergraduates according to gender Differences, Perspectives in Nursing Science, (2013), Vol.10, No.2, pp.141-150.

[20] B. Y. Choi, The effects of intrinsic extrinsic work value on career decision self efficacy according to gender in College students, The Korea Journal of Youth Counseling, (2013), Vol.21, No.1, pp.1-17, DOI: DOI : 10.35151/kyci.2013.21.1.001 